\title{
Multi-objective Optimization of Pneumatic Mixing Systems for Anaerobic Digesters: A Hybrid Technique of Statistical Modeling and Numerical Simulations
}

\author{
Mahmood Mahmoodi-Eshkaftaki ( $\sim$ m.mahmoodi5@gmail.com) \\ Jahrom University https://orcid.org/0000-0001-7263-3921 \\ Hossein Rahmanian-Koushkaki \\ Jahrom University
}

\section{Research Article}

Keywords: Biogas injection parameters, Computational fluid dynamics, Image processing technique, Optimization, Pneumatic mixer.

Posted Date: October 26th, 2021

DOl: https://doi.org/10.21203/rs.3.rs-945410/v1

License: (c) (1) This work is licensed under a Creative Commons Attribution 4.0 International License. Read Full License

Version of Record: A version of this preprint was published at Waste and Biomass Valorization on January 28th, 2022. See the published version at https://doi.org/10.1007/s12649-022-01703-2. 
Multi-Objective Optimization of Pneumatic Mixing Systems for Anaerobic Digesters: A Hybrid Technique of Statistical Modeling and Numerical Simulations

\author{
Mahmood Mahmoodi-Eshkaftaki*, Hossein Rahmanian-Koushkaki
}

Department of Mechanical Engineering of Biosystems, Jahrom University, P.O. Box 74135111, Jahrom, Iran.

Email: $\underline{\text { m.mahmoodi5@gmail.com, m.mahmoodi5@jahromu.ac.ir }}$ 


\section{Abstract}

Development a suitable mixing system for biogas plants is one of the most important factors to degrade organic matters in digesters. Therefore, pneumatic and mechanical mixing systems were integrated with their optimum conditions to produce a suitable strategy for mixing slurry. Pneumatic mixing parameters were investigated using computational fluid dynamics and image processing techniques. The mixing characteristics and biogas compounds were modeled according to biogas injection parameters, and integrated into the desirability function to determine the optimum conditions. The models indicated that for lower injection repetition in different injection positions, a higher mass flow rate was needed to improve the mixing characteristics and $\mathrm{CH}_{4}$ content. Optimization of these parameters showed that the best amounts of injection mass rate, injection pressure and injection repetition were $0.02 \mathrm{~g} / \mathrm{s}, 2.84$ bar and 3 times, respectively, and their optimum ranges were $0.015-0.028 \mathrm{~g} / \mathrm{s}, 1.5-4.7 \mathrm{bar}$ and 1-4 times. However, the best injection was injection through mixer and injection in floor of digester for 2 or 3 times in $24 \mathrm{~h}$. From the optimum ranges, some amounts were investigated in the digesters using the computational fluid dynamics, and the determined mixing characteristics were in agreement with findings of the image processing method.

\section{Statement of Novelty}

Nowadays, the researchers in bio-system engineering focus on development of biogas plants to enrich biogas production and increase their performance. One of the most important factors for this goal is the mixing system. The novelty of this article is to develop a hybrid optimization technique, integrating RSM and desirability analysis, to determine the optimum conditions of pneumatic mixing process, in which CFD simulations and calorimetric method base image processing techniques are utilized to study the mixing process. 
Keywords: Biogas injection parameters; Computational fluid dynamics; Image processing technique; Optimization; Pneumatic mixer.

\begin{tabular}{llll}
\hline Nomenclature & & \\
$\mathrm{AR}^{2}$ & Adjusted $\mathrm{R}^{2}$ & $\mathrm{TFM}$ & Two-fluid model \\
$\mathrm{AP}$ & Adequate precision & $x$ & Independent variable \\
$\mathrm{CFD}$ & Computational fluid dynamics & $\mathrm{y}$ & Dependent variable \\
$\mathrm{Col}_{\mathrm{r}}$ & Color rating & $\alpha$ & Volume fraction \\
$\mathrm{C}_{\mathrm{D}}$ & Drag coefficient & $\dot{\gamma}$ & Shear rate \\
$\mathrm{d}$ & Diameter of bubbles or droplets & $\mu$ & Viscosity \\
$\mathrm{df}$ & Degree of freedom & $\vec{v}$ & Velocity \\
$\mathrm{DPM}$ & Discrete particle method & $\sigma$ & Turbulent Prandtl numbers \\
$\mathrm{f}$ & Drag function & $=$ & Stress-strain tensor \\
$\mathrm{G}$ & Generation & $\tau$ & Particulate relaxation time \\
$\overrightarrow{\mathrm{g}}$ & Represents gravity & $\tau_{\mathrm{p}}$ & \\
$\mathrm{LF}$ & Lack of fit & & \\
$\dot{\mathrm{m}}$ & Mass transfer & & \\
$\mathrm{P}$ & Static pressure shared by all phases & $\mathrm{k}$ & Turbulent kinetic energy \\
$\mathrm{PR}$ & Predicted $\mathrm{R}^{2}$ & $\mathrm{~m}$ & Mixture \\
$\mathrm{R}^{2}$ & Coefficient of determination & $\mathrm{p}$ & Phase $\mathrm{p}$ \\
$\mathrm{r}_{\mathrm{i}}$ & Response's relative importance & $\mathrm{pq}$ & Phase $\mathrm{p}$ to phase $\mathrm{q}$ \\
$\vec{R}$ & Interaction force & $\mathrm{q}$ & Phase $\mathrm{q}$ \\
$\mathrm{Re}$ & Reynolds number & $\mathrm{qp}$ & Phase $\mathrm{q}$ to phase $\mathrm{p}$ \\
$\mathrm{RSM}$ & Response surface methodology & $\mathrm{t}$ & Turbulent \\
$\mathrm{SE}$ & Standard error & $\varepsilon$ & Dissipation rate of turbulent kinetic energy \\
$\mathrm{t}_{\mathrm{mix}}$ & Mixing time & & \\
\hline & & &
\end{tabular}

\section{Introduction}

The development of biogas plants to enrich $\mathrm{CH}_{4}$ production and increase their energy performance is very important. One of the most important factors for this goal is the mixing system. Mixing the slurries in the digesters helps to degrade organic matters and increase biogas output [1]. The purpose of the mixing process is to distribute the nutrients in the digester uniformly [2], to shape a suitable suspension of liquid and solid part [3], to avoid sedimentation of particles [1, 3], to ensure uniform heat distribution [2], to prevent foam formation and to 
enable gas lift from the digestion substrate [2]. There are several mixer technologies commercially known as mechanical, hydraulic or pneumatic mixing systems [4]. Mechanical mixing is the most common mixing type being used today, and uses different types of impellers and agitators. As it has been revealed, the mechanical mixers have the highest power efficiency per volume unit mixed while the pneumatic mixers have the lowest [4]. The common pneumatic mixing systems in the biogas plants work with biogas recirculation through the digester. The use of these two mixer types together leads to the benefits of both systems.

Different studies have been done on the mechanical mixers to determine the suitable impeller type, impeller position in the digester and impeller dimension in order to increase the plant performance energetically $[4,5]$, and improve the biodegradation of organic matters $[5$, 6]. As reported in the literature, integrating the mechanical and pneumatic mixing systems can increase the efficiency of biogas digesters in low energy consumption [7]. However, the optimization of pneumatic mixers has not been investigated, especially in co-using with mechanical mixers. The pneumatic mixers in biogas plants can influence of different parameters such as biogas injection mass flow rate, injection pressure, injection position in the digester, injection repetition, etc. A mixing process in optimum conditions improves the biodegradation of organic matters in the digesters, decreases mixing time $\left(\mathrm{t}_{\mathrm{mix}}\right)$ and purifies the biogas. Determination of the injection parameters during the digestion is very difficult, computed simulation models of computational fluid dynamics (CFD) are appropriate approaches to determine the injection parameters [8]. The mixing characteristics of the slurry in the digesters have been studied using CFD analyses [9, 10, 11]. According to the CFD analyses, the mixing process is affected by digester size [12], digester type [9], mixer type [10], etc. Two mixer types, pneumatic and mechanical mixers, were studied by $\mathrm{Wu}$ [10] using a CFD-based model. The performance of pneumatic mixing system was evaluated in a digester with four gas mixing designs. Eulerian multiphase flow approach was considered during the 
modeling process, and the indices of average velocity and a uniformity index for velocity were selected to determine the best design of the gas mixer. Two different approaches of CFD modeling are available for predicting multiphase flow in the digesters, namely EulerianEulerian (two-fluid model or TFM) and Eulerian-Lagrangian (discrete particle method or DPM). Because of TFM modeling technique requires fewer computational resources compared with the DPM method, it is selected by the researchers for simulation of multiphase flow in the digesters $[9,10]$.

Biodegradation improvement of the organic matters in the biogas digester leading to decrease impurities such as $\mathrm{H}_{2} \mathrm{~S}, \mathrm{H}_{2} \mathrm{O}$ and $\mathrm{CO}_{2}$ from the biogas and increase $\mathrm{CH}_{4}[13,14,15]$. The pneumatic mixing systems using biogas recirculation not only helping to mix the slurry but also can purify the biogas biologically $[7,16,17]$. This shows the pneumatic mixing process can improve the biodegradation of organic matters in the biogas digesters. It remains to consider the optimum conditions of biogas injection for the pneumatic mixers. An integrated linear and nonlinear optimization method such as response surface methodology (RSM) shows good accuracy for similar problems [18]. However, to optimize multiple responses, the RSM alone is not very accurate, especially when optimum ranges of parameters should be determined. Thus, a desirability function can be integrated by RSM to determine the optimum values and ranges. Therefore, the goals of the present work are to (i) utilize the CFD simulations and calorimetric method base image processing techniques for studying the mixing process, and (ii) employ a hybrid optimization technique, integrating RSM and desirability analysis, to determine the optimum conditions of biogas injection in the cases of optimum absolute values and optimum ranges.

\section{Material and methods}

\section{Biogas setup}


The diameter, height, and wall thickness of the digesters were $0.57,0.9$ and $0.01 \mathrm{~m}$, respectively, and their volumes were $0.22 \mathrm{~m}^{3}$. A mechanical mixer with four blade marine impeller stirred material in each digester. Impeller dimensions including impeller diameter, blade thickness, blade length and blade width were $0.32,0.004,0.1$ and $0.04 \mathrm{~m}$, respectively. These stirred digesters were constructed according to rules stated in Mahmoodi-Eshkaftaki and Ebrahimi $[5,15]$. Three similar stirred digesters were constructed for the experiments, and just their biogas injection position was different. Fig. 1 shows a digester with the pneumatic mixing system via biogas recirculation process from the bottom of digester. For biogas recirculation, a compression system equipped by a $0.1 \mathrm{~kW}$ compressor with delivery pressure up to $3000 \mathrm{kPa}$ was used to compress the biogas and recirculate it into the digester. The compressed biogas was injected into the digester through one of these three positions, floor of digester, through the mixer, and lateral wall at a height of $10 \mathrm{~cm}$ from the floor. Temperature of the digesters was kept at $37^{\circ} \mathrm{C}$ using a solar heating system.

\section{Fig. 1}

\section{Slurry preparation}

A mixture of cow manure, municipal waste and fruit waste diluted with tap water was prepared to be used in the anaerobic digestion experiments. According to our previous work in laboratory scale, the optimum anaerobic digestion was acquired with the amounts of $42 \%, 56 \%$ and $2 \%$ of cow manure, municipal waste and kitchen waste pretreated with $3 \%$ and $1 \%$ of $\mathrm{NaOH}$ and $\mathrm{H}_{2} \mathrm{O}_{2}$, respectively, in which $\mathrm{CH}_{4}$ production reached to the most amount [15]. To produce the slurry for each state, these amounts of the substrates were grinded using a force mill and mixer part, diluted with $40 \%$ water, enriched with $20 \%$ inoculum (from the biogas plant of Jahrom university), and pretreated with $3 \%$ and $1 \%$ of $\mathrm{NaOH}$ and $\mathrm{H}_{2} \mathrm{O}_{2}$, respectively. The headspace of the digesters was purged using $\mathrm{N}_{2}$. The mixing process was done using both 
pneumatic and mechanical mixers. Different parameters of the pneumatic mixing system would be optimized in this research to improve the mixing process and enrich $\mathrm{CH}_{4}$. For this purpose, an optimal experimental design based on RSM was used.

\section{Experimental design}

To determine the best strategy for the pneumatic mixing system using biogas recirculation, four effective parameters of inlet biogas were selected. The parameters were mass flow rate $(0.009,0.017$ and $0.025 \mathrm{~g} / \mathrm{s})$, biogas injection pressure $(1,2.5$ and 5 bar), repeat of injection in each $24 \mathrm{~h} \mathrm{(2,3} \mathrm{and} 4$ times), and injection position ( $0:$ lateral wall at a height of $10 \mathrm{~cm}$ from the floor, 1: floor of digester and 2: through the mixer). The mass rates were measured according to biogas inlet velocities of $0.044,0.084$ and $0.123 \mathrm{~m} / \mathrm{s}$, respectively, with the slurry density of $1080 \mathrm{~kg} / \mathrm{m}^{3}$ and nozzle cross section of $0.000177 \mathrm{~m}^{2}$. The experiments of anaerobic digestion were done based on a randomized optimal design using RSM in the biogas digesters. Summary of the experiments is reported in Table 1 . As shown the independent variables are the biogas injection parameters and the responses are the biogas compounds and mixing characteristics.

\section{Table 1}

In the experimental design, 15 points were required to develop models, three points to estimate the lack of fit (LF), and three points to replicate the experiments [19]. For multivariate modeling of the responses, a quadratic equation (Eq. 1) was used as the basic form of the models.

$$
y(x)=a_{0}+\sum_{i=0}^{N} a_{i} x_{i}+\sum \sum_{i<j}^{N} a_{i j} x_{i} x_{j}, i=1,2, \ldots, N
$$


where $y$ is transformation cases of the responses (dependent variables), $x_{i}$ related to the amounts of the biogas injection parameters (independent variables), $a_{i}$ is model coefficients, and $\mathrm{N}$ is the number of independent variables $(\mathrm{N}=4)$ described in Table 1 [20].

\section{Measured parameters}

The biogas compounds including $\mathrm{CH}_{4}, \mathrm{H}_{2} \mathrm{~S}, \mathrm{CO}$ and $\mathrm{O}_{2}$ were determined using a multifunction gas detector brand GMI Ltd model GT43 [5, 15], and $\mathrm{CO}_{2}$ was measured using $\mathrm{CO}_{2}$ meter model TESTO 535 [7].

The slurry mixing characteristics including mixing time $\left(t_{\text {mix }}\right)$ and color rating $\left(\mathrm{Col}_{\mathrm{r}}\right)$ were determined using a single indicator system developed by image processing techniques. To determine the $\mathrm{t}_{\mathrm{mix}}$ and $\mathrm{Col}_{\mathrm{r}}$ for the digesters, water was used as the basic liquid in the colorimetric method because not only its mixing pattern remains constant through visual inspection [21] but also its density is close to the slurry used in this research. For this purpose, potassium permanganate solution was titrated to the digesters according to the experiment points, and its separation in the digesters was detected by color analyses as described in our previous study [5]. For color analysis, the image processing base image segmentation algorithm was used to track the color changes (Fig. 2). The input images improved by preprocessing techniques and then detected color changes were tracked according to the method reported in Mahmoodi-Eshkaftaki and Ebrahimi [5] researches. A coupled multilevel thresholding based Otsu's method and label connected components was used to determine the color changes. The $t_{\text {mix }}$ and $\mathrm{Col}_{\mathrm{r}}$ were automatically determined using the software based on how long it takes the distracted objects get $99.5 \%$ of the digester surface.

Fig. 2

\section{Optimization process}


Desirability function was used to simultaneously optimize all affecting parameters to achieve the best biogas injection conditions. This method finds operating conditions $x$ providing the most desirable response values [22]. For each response $y_{i}(x)$, the desirability function $d_{i}\left(y_{i}\right)$ got values between 0 to 1 to the possible values of $y_{i} ; d_{i}\left(y_{i}\right)=0$ represented an undesirable value of $y_{i}$, and $d_{i}\left(y_{i}\right)=1$ represented a highly desirable value. The overall desirability was calculated using the geometric mean of the individual desirabilities (Eq. 2). The $y_{i}$ values were replaced by fitted response values $\hat{y}_{i}$ as suggested in the literature [18].

$$
\begin{aligned}
& D=\left[\prod_{i=1}^{n} d_{i}\left(y_{i}\right)^{r_{i}}\right]^{\frac{1}{\sum_{i}}} \\
& d_{i}\left(\hat{y}_{i}\right)=\left\{\begin{array}{lcl}
0 & \text { if } \hat{y}_{i}(x)<L_{i} \\
\left(\frac{\hat{y}_{i}(x)-L_{i}}{T_{i}-L_{i}}\right) & \text { if } L_{i} \leq \hat{y}_{i}(x) \leq T_{i} & \text { If a response is to be maximized. } \\
1 & \text { if } \hat{y}_{i}(x)>T_{i} & T_{\mathrm{i}} \text { denoting a large enough value for the response. }
\end{array}\right.
\end{aligned}
$$

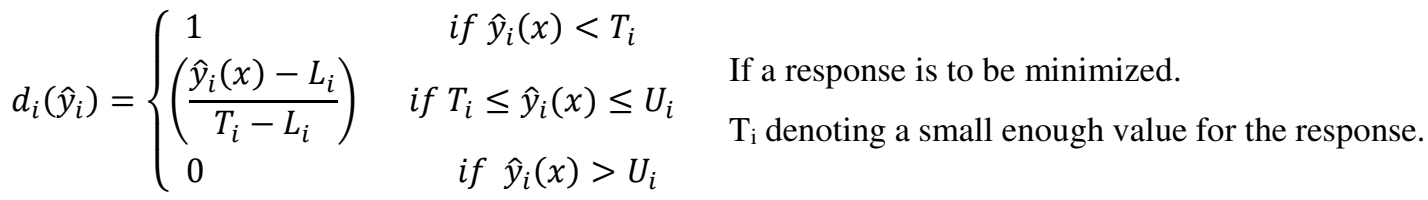

In this equation, $N$ is the number of responses (7), $\mathrm{r}_{\mathrm{i}}$ is response's relative importance to the other responses. $L_{i}, U_{i}$ and $T_{i}$ are the lower, upper and target values, respectively, which are desired for response $y_{i}\left(\mathrm{~L}_{\mathrm{i}} \leq \mathrm{T}_{\mathrm{i}} \leq \mathrm{U}_{\mathrm{i}}\right)$ as described in the literature [18]. In this study, the $\mathrm{r}_{\mathrm{i}}$ varied from the least important (2) to the highest important (5) for the responses.

\section{Development of CFD multiphase flow model}

Because of the multiphase and turbulent nature of pneumatic and mechanical mixing of the slurry in the digesters, governing equations of the current CFD simulations are mass and momentum conservations, interphase momentum transfer and turbulence transport.

The following assumptions were considered in developing the theoretical model.

a. External body force, virtual mass force and lift force were negligible.

b. The system was isothermal at a constant temperature of $37^{\circ} \mathrm{C}$. 
c. The phases were incompressible fluids.

The mass conservation equation for phase $\mathrm{q}$ is expressed as Eq. (3).

$$
\frac{\partial\left(\alpha_{\mathrm{q}} \rho_{\mathrm{q}}\right)}{\partial \mathrm{t}}+\nabla \cdot\left(\alpha_{\mathrm{q}} \rho_{\mathrm{q}} \overrightarrow{\mathrm{v}}_{\mathrm{q}}\right)=\sum_{\mathrm{p}=1}^{\mathrm{n}}\left(\dot{\mathrm{m}}_{\mathrm{pq}}-\dot{\mathrm{m}}_{\mathrm{qp}}\right)
$$

where $\alpha_{q}$ is the volume fraction of phase $q, \rho_{q}$ is the density of phase $q, \vec{v}_{q}$ is the velocity of phase $\mathrm{q}, \dot{\mathrm{m}}_{\mathrm{pq}}$ is the mass transfer from phase $\mathrm{p}$ to phase $\mathrm{q}, \dot{\mathrm{m}}_{\mathrm{qp}}$ is the mass transfer from phase $\mathrm{q}$ to phase $\mathrm{p}$ and $\mathrm{n}$ is the number of phases.

The concept of volume fraction for each phase is used to define the volume of that phase defined as Eq. (4). It should be noted that sum of the volume fractions of the phases is equal to one.

$$
\mathrm{V}_{\mathrm{q}}=\int \alpha_{\mathrm{q}} \mathrm{dV}
$$

The momentum conservation equation is expressed as Eq. (5).

$$
\frac{\partial}{\partial \mathrm{t}}\left(\alpha_{\mathrm{q}} \rho_{\mathrm{q}} \overrightarrow{\mathrm{v}}_{\mathrm{q}}\right)+\nabla \cdot\left(\alpha_{\mathrm{q}} \rho_{\mathrm{q}} \overrightarrow{\mathrm{v}}_{\mathrm{q}} \overrightarrow{\mathrm{v}}_{\mathrm{q}}\right)=-\alpha_{\mathrm{q}} \nabla \mathrm{P}+\nabla \cdot \bar{\tau}_{\mathrm{q}}+\alpha_{\mathrm{q}} \rho_{\mathrm{q}} \overrightarrow{\mathrm{g}}+\sum_{\mathrm{p}=1}^{\mathrm{n}}\left(\overrightarrow{\mathrm{R}}_{\mathrm{pq}}+\dot{\mathrm{m}}_{\mathrm{pq}} \overrightarrow{\mathrm{V}}_{\mathrm{pq}}-\dot{\mathrm{m}}_{\mathrm{qp}} \overrightarrow{\mathrm{V}}_{\mathrm{qp}}\right)
$$

In this equation, $\mathrm{P}$ denotes as static pressure shared by all phases, $\bar{\tau}_{\mathrm{q}}$ is stress-strain tensor for phase q, $\vec{g}$ represents gravity, $\vec{R}_{\mathrm{pq}}$ is the interaction force between phases, $\overrightarrow{\mathrm{V}}_{\mathrm{pq}}$ and $\overrightarrow{\mathrm{V}}_{\mathrm{qp}}$ are interphase velocities. The interaction force can be presented as Eq. (6) [23].

$$
\sum_{\mathrm{p}=1}^{\mathrm{n}} \overrightarrow{\mathrm{R}}_{\mathrm{pq}}=\sum_{\mathrm{p}=1}^{\mathrm{n}} \frac{\alpha_{\mathrm{p}} \alpha_{\mathrm{q}} \rho_{\mathrm{p}} \mathrm{f}}{\tau_{\mathrm{p}}}\left(\overrightarrow{\mathrm{V}}_{\mathrm{p}}-\overrightarrow{\mathrm{V}}_{\mathrm{q}}\right)
$$

where $\tau_{\mathrm{p}}$ is the particulate relaxation time and $\mathrm{f}$ is the drag function and. These two parameters were calculated with Eqs. (7) and (8).

$$
\tau_{p}=\frac{\rho_{p} d_{p}^{2}}{18 \mu_{p}}
$$




$$
\mathrm{f}=\frac{\mathrm{C}_{\mathrm{D}} \operatorname{Re}}{24}
$$

In the mentioned equations, $\mathrm{C}_{\mathrm{D}}$ is the drag coefficient which is a function of the relative Reynolds number $(\operatorname{Re})\left(\right.$ Eq. 9), $d_{p}$ is the diameter of bubbles or droplets of phase $p$, and $\mu_{p}$ is the viscosity of phase $p$.

$$
C_{D}= \begin{cases}24\left(1+0.15 \operatorname{Re}^{0.657}\right) / \mathrm{Re} & \mathrm{Re} \leq 1000 \\ 0.44 & \mathrm{Re}>1000\end{cases}
$$

The mixture $\mathrm{k}-\varepsilon$ turbulence model was used to describe the effect of turbulence fluctuations with standard wall function near walls as bellow:

$$
\begin{aligned}
& \frac{\partial}{\partial \mathrm{t}}\left(\rho_{\mathrm{m}} \mathrm{k}\right)+\nabla \cdot\left(\rho_{\mathrm{m}} \overrightarrow{\mathrm{v}}_{\mathrm{m}} \mathrm{k}\right)=\nabla \cdot\left(\frac{\mu_{\mathrm{t}, \mathrm{m}}}{\sigma_{\mathrm{k}}} \nabla \mathrm{k}\right)+\mathrm{G}_{\mathrm{k}, \mathrm{m}}-\rho_{\mathrm{m}} \varepsilon \\
& \frac{\partial}{\partial \mathrm{t}}\left(\rho_{\mathrm{m}} \varepsilon\right)+\nabla \cdot\left(\rho_{\mathrm{m}} \overrightarrow{\mathrm{v}}_{\mathrm{m}} \varepsilon\right)=\nabla \cdot\left(\frac{\mu_{\mathrm{t}, \mathrm{m}}}{\sigma_{\varepsilon}} \nabla \varepsilon\right)+\frac{\varepsilon}{\mathrm{k}}\left(\mathrm{C}_{1 \varepsilon} \mathrm{G}_{\mathrm{k}, \mathrm{m}}-\mathrm{C}_{2 \varepsilon} \rho_{\mathrm{m}} \varepsilon\right)
\end{aligned}
$$

where $\rho_{\mathrm{m}}, \overrightarrow{\mathrm{v}}_{\mathrm{m}}$, and $\mu_{\mathrm{t}, \mathrm{m}}$ are mixture density, mixture velocity and turbulent viscosity of the mixture, respectively. In addition, $\mathrm{G}_{\mathrm{k}, \mathrm{m}}$ is the generation of turbulent kinetic energy, $\sigma_{\mathrm{k}}$ and $\sigma_{\varepsilon}$ are turbulent Prandtl numbers for $\mathrm{k}$ and $\varepsilon$, and $\mathrm{C}_{1 \varepsilon}$ and $\mathrm{C}_{2 \varepsilon}$ are constants.

According to the literature, the manure slurry exhibits non-Newtonian pseudo-plastic fluid behavior [24].

$$
\mu=k \dot{\gamma}^{n-1}
$$

In above equation, $\mathrm{k}$ is the consistency coefficient, $\dot{\gamma}$ is the shear rate, and $\mathrm{n}$ is the powerlaw index.

The commercial CFD code ANSYS-Fluent 18.0 was used for simulations. A twodimensional, pressure-based, implicit, double precision and transient algorithm were chosed to solve the governing differential equations. The TFM under the Eulerian-Eulerian model was active, in which the slurry was considered as the primary phase while the biogas was treated as 
the secondary phase. The drag function between the phases was adjusted as Schiller-Naumann. The boundary and initial conditions for the phases were considered as below:

a. No-slip boundary conditions were imposed on all wall surfaces.

b. The mass flow inlet boundary condition was used for the injection of the biogas.

c. The moving wall boundary condition was used for the impeller.

d. At the initial time, the height of slurry in the digester was set as $60 \mathrm{~cm}$.

e. At the moment of biogas injection, no gas existed in the slurry zone.

The phase coupled SIMPLE scheme was set for pressure-velocity coupling. Also, discretization schemes were QUICK for volume fraction and momentum and first-order upwind for the other variables. A time step of $0.01 \mathrm{~s}$ was chosen. Under- relaxation factors were $0.3,0.5,0.5,0.5,0.3,0.2,0.2$ and 0.2 for pressure, density, body force, momentum, volume fraction, turbulent kinetic energy, turbulent dissipation rate and turbulent viscosity, respectively. The convergence criteria were chosen as $10^{-6}$ for all the variables and a final convergence was achieved when the monitored value remained almost constant.

\section{Grid independence and time step study}

A high quality grid has been used for the simulation process. The calculation domain (57 $\mathrm{cm}$ width $\times 90 \mathrm{~cm}$ height) was divided into structured tetrahedral grid. The grid was created in two dimensions with 179600 cells. Several grids with different mesh resolutions were generated to perform the grid-independence study. Finally, the element number 179600 was chosen for numerical simulations. The results of the grid study are not shown for brevity. The gird quality was examined to ensure that the high skewness and high aspect ratio was below 0.9 and 5 , respectively.

\section{Results and disscusion}


As shown in Table 1, all the biogas injection factors were created as a numeric type (coded: $-1-1)$. The response factors produced relatively wide ranges of the biogas compounds and mixing characteristics that were suitable for model development and optimization process. For this purpose, effect of the biogas injection factors on the responses were studied using the multivariate regression analysis. To model the responses in the regression analysis, different transformations were considered, and the best ones were selected as shown in Table 1. To optimize the parameters, the desirability function developed by overlaying the responses would be maximized.

\section{Models}

For the multivariate regression analysis, different functions by varying transformation $y$ as square root, natural log, base $10 \log$, inverse sqrt, inverse and power were considered to model the biogas compounds and mixing characteristics, and the best ones were selected. As shown in Table 1 for the responses, the best transformation was power transformation. The accuracy of the models was considered by calculating the coefficient of determination $\left(\mathrm{R}^{2}\right)$, adjusted $\mathrm{R}^{2}$ $\left(\mathrm{AR}^{2}\right)$, predicted $\mathrm{R}^{2}\left(\mathrm{PR}^{2}\right)$, adiquate precision $(\mathrm{AP})$, and $\mathrm{p}$-value $(\mathrm{p}<0.1$ denoted significant effect of the model). For a good model, the p-value of the model should be significant, and the p-value of the LF should be non-significant [19]. Some of the variables that existed in the raw models were not significant ( $p>0.1$ ), and better to delete them from the models and improve the final models [25]. In this content, the best modified models selected according to statistics for the responses were determined as Eqs. (13) - (19) which was illustrated in Table 2. Further, the model summary statistics have been given in Table 2. As shown, the model's p-values of all the responses were significant, and their LF p-values were not significant. These models were made based on the coded terms. In a coded equation, coefficients of factors identify the relative impact of the factors on the responses [20]. 


\section{Table 2}

The Eqs. (13) - (15), power transformation cases of improved multivariate regression equations, could estimate the $\mathrm{CH}_{4}, \mathrm{H}_{2} \mathrm{~S}$ and $\mathrm{CO}_{2}$ contents very well (their $\mathrm{R}^{2}>0.76, \mathrm{AR}^{2}>0.62$, $\mathrm{PR}^{2}>0.34$ and $\mathrm{AP}>8.83$ ). The model F-values higher than 5.7 implied that the models were significant. LF F-values higher than 0.29 denoted that they were not significant relative to the pure errors for these three models. The AP values of the models were higher than 8.83 indicating adequate signals for these models. Therefore, they could be used to navigate the design space. These statistical parameters show that the models could estimate $\mathrm{CH}_{4}, \mathrm{CO}_{2}$ and $\mathrm{H}_{2} \mathrm{~S}$ with high accuracy. Larger coefficients of the terms having $x_{1}$ and $x_{4}$ in Eqs. (13) and (14), and $x_{2}$ and $x_{4}$ in Eq. (15) implied the significant effect of the injection mass rate and injection position on $\mathrm{CH}_{4}$ and $\mathrm{H}_{2} \mathrm{~S}$ contents, and injection pressure and injection position on $\mathrm{CO}_{2}$ content.

The $\mathrm{CO}$ and $\mathrm{O}_{2}$ contents were estimated by Eqs. (16) and (17), improved multivariate regression equations based on the injection parameters. The quantities of $\mathrm{R}^{2}, \mathrm{AR}^{2}, \mathrm{PR}^{2}$ and $\mathrm{AP}$ were higher than $0.59,0.45,0.19$ and 9.19, respectively. Their model F-values higher than 4.3 implied that the models were significant. Their LF F-values were not significant relative to the pure errors. The AP values of these models were also higher than 9 indicating adequate signals for the models to be used to navigate the design space. These reasons indicated the Eqs. (16) and (15) were suitable for $\mathrm{CO}$ and $\mathrm{O}_{2}$ estimation. The larger coefficients of the model terms including $x_{4}$ appeared a higher effect of biogas injection position on $\mathrm{CO}$ and $\mathrm{O}_{2}$ contents. The absence of $x_{3}$ in the terms indicated that the effect of injection repetition was not significant on $\mathrm{CO}$ and $\mathrm{O}_{2}$ contents.

Eqs. (18) and (19), power transformation of the improved multivariate regression equations, could estimate the $\mathrm{Col}_{\mathrm{r}}$ and $\mathrm{t}_{\mathrm{mix}}$ with high accuracy (their $\mathrm{R}^{2}>0.92, \mathrm{AR}^{2}>0.89, \mathrm{PR}^{2}>$ 0.85 and AP> 17.41). The model F-values higher than 34.97 implied that the models were significant. LF F-values higher than 1.21 denoted that they were not significant relative to the 
pure errors. The AP values of the models were higher than 17.41 indicating adequate signals for these models to be used to navigate the design space. These results indicated that the models had high accuracies for estimation the mixing characteristics. The larger coefficients of the model terms including $x_{1}$ indicated a higher effect of biogas injection mass rate on color rating and mixing time. The terms including $x_{3}$ were eliminated from these two models because the effect of injection repetition was not investigated for the mixing characteristics.

Totally, these models had high accuracies for estimation of the biogas compounds and mixing characteristics confirming that they can be successfully used in the optimization process. The high accuracy of the models is better seen in Fig.3. Fig. 3 shows predicted values of the biogas compounds and the mixing characteristics versus actual values. As shown, the dispersion of predicted values versus actual values was suitable.

\section{Fig. 3}

The effects of the significant interactions of injection parameters on the biogas compounds and the mixing characteristics are graphically represented in Fig. 4. As shown the effect of biogas pressure was not illustrated because the mass rate was calculated according to biogas pressure (using CFD method), and therefore their trends were nearly similar. It is shown in Fig. 4 that for biogas injection in similar mass rates, $\mathrm{CH}_{4}$ was more enriched for injection position through the mechanical mixer. Furthermore, for lower injection repetition, we needed a higher mass rate to produce high $\mathrm{CH}_{4}$ content. With increasing the injection mass rate, $\mathrm{H}_{2} \mathrm{~S}$ and $\mathrm{CO}_{2}$ contents of the biogas output increased. Biogas injection from the lateral wall of the digesters could not eliminate $\mathrm{H}_{2} \mathrm{~S}$ and $\mathrm{CO}_{2}$ from the biogas significantly. With increasing the mass rate for different injection positions, $\mathrm{Col}_{\mathrm{r}}$ increased rapidly and thus $\mathrm{t}_{\mathrm{mix}}$ decreased. As shown in the figure, injection from the lateral wall of digesters and through the mixer had a similar effect on mixing characteristics, and injection from the floor of digesters produced the least $\mathrm{Col}_{\mathrm{r}}$ (or the 
most $\left.t_{\text {mix }}\right)$. These regression analyses show the importance of having a suitable strategy for biogas injection in the pneumatic mixers.

\section{Fig. 4}

\section{Optimization process}

Slurry can best be mixed using the pneumatic mixer when the injection parameters are in optimum conditions. As described above different injection parameters have influence on the mixing process. The optimization of these parameters is essential for the successful operation of the anaerobic digestion, though it is difficult to carry out [26]. For desirable digestion, the biogas compounds and the mixing characteristics should be optimized. The optimization process was done with definition of constraints for the biogas compounds and mixing characteristics. As described for the constraints, $\mathrm{CH}_{4}, \mathrm{Col}_{\mathrm{r}}$ and $\mathrm{t}_{\mathrm{mix}}$ were maximized with $\mathrm{r}_{\mathrm{i}}$ equal to 5, 4 and 4, respectively, while the other responses were minimized.

Eight runs were obtained by running the models together in order of high desirability and the first three runs have been reported in Table 3. These runs were used to illustrate the effect of changes in the biogas injection factors on the biogas compounds and mixing characteristics. The best run (Run 1) revealed the highest desirability, and was selected to report the optimum absolute amounts of the parameters. Accordingly, the best amounts of injection mass rate, injection pressure, injection repetition and injection position were $0.02 \mathrm{~g} / \mathrm{s}, 2.84 \mathrm{bar}, 2.64$ (rounded 3 times) and 1.95 (rounded 2), respectively. Considering the eight runs specified that the best injection repetition were 2 or 3 times in $24 \mathrm{~h}$. These optimum runs were precise and reliable because they were determined by a hybrid optimization technique, integrating accurate models and desirability analysis. Similar optimization methods were developed in other studies for different parameters $[18,27,28,29,30]$. 


\section{Table 3}

The overall desirability function $\mathrm{D}(\mathrm{x})$ for the best run (Run 1) according to the biogas injection factors is illustrated in Fig. 5. The function $\mathrm{D}(\mathrm{x})$ was not quite flat in the vicinity of the optimum absolute amounts indicating that variations around the maximum desirability (0.809) could change the overall desirability drastically. As shown in Fig. 5, the highest desirability value (highlighted in the plots) is within the tested ranges of the factors; and thus, the optimum absolute amounts of the injection parameters can be understood from the plots reliably.

\section{Fig. 5}

The optimum regions of the injection parameters are illustrated in Fig. 6. These regions were determined by overlaying all the responses according to defined constraints. The suitable ranges of biogas injection factors were extracted from the optimum regions. Fig. 6(a) shows the optimum region in which $\mathrm{CH}_{4}$ and $\mathrm{Col}_{\mathrm{r}}$ were maximized and the other responses were minimized (predefined constraints). The optimum regions detected in Fig. 6(b and c) were determined using supplementary constraints in addition to predefined constraints. Optimum region in Fig. 6(b) produced by overlaying all the responses in which $\mathrm{CH}_{4}$ and $\mathrm{Col}_{\mathrm{r}}$ could only get the values higher than 0.9 their maximums and the other responses get the values lower than 0.9 their minimums from the tested ranges. Using this limitation, the optimum region was not found. Fig. 6(c) shows the optimum region in which $\mathrm{CH}_{4}$ and $\mathrm{Col}_{\mathrm{r}}$ could get the values higher than 0.7 their maximums and the other responses could get the values lower than 0.7 their minimums of the tested ranges. All the models and their standard error were overlayed according to the above limitations to determine the optimum regions. As shown from Fig. 6(a), suitable mass rates were ranged from bellow 0.009 to after $0.025 \mathrm{~g} / \mathrm{s}$ or injection repetition 1 to 5 times in $24 \mathrm{~h}$ which were higher than the tested ranges. Therefore, this optimum region was not reliable. To determine a more suitable region, the range of each response was further 
limited until attached to the best region as shown in Fig. 6(c). The best range for mass flow rate was $0.015-0.028 \mathrm{~g} / \mathrm{s}$, injection pressure was $1.5-4.7 \mathrm{bar}$, injection position was 2 , and injection repetition was 1-4 times. With further limitation, $\mathrm{CH}_{4}$ and $\mathrm{Col}_{\mathrm{r}}$ were higher than 0.5 their maximums and the other responses were lower than 0.5 their minimums, the injection position of 1 was also suitable for the pneumatic mixing system.

\section{Fig. 6}

To investigate in detail the mixing process of the slurry with optimum conditions of the pneumatic mixer, the volume fraction contours of the slurries from CFD modeling were studied. The CFD was used for some of the optimum conditions in the vertical cross-section of the plane parallel to the feeding pipes to get an overall picture of the flow pattern. Fig. 7 shows the volume fraction contours of the slurry for biogas injection from the floor of the digester with optimum mass rate of $0.015 \mathrm{~g} / \mathrm{s}$. The volume fraction contours of the slurry differed as follows: Firstly, the injected biogas messed up the region below the impeller and risen quickly in the slurry $\left(t_{m i x}=10 \mathrm{~s}\right)$. Secondly, the slurry upper the impeller mixed significantly with both injected biogas and mechanical mixer $\left(t_{\text {mix }}=40 \mathrm{~s}\right)$. Then the region below the impeller started to mess up powerfully $\left(\mathrm{t}_{\mathrm{mix}}=80 \mathrm{~s}\right)$. As the end of the stirring time approaches, unmixed region below the impeller increased $\left(t_{\operatorname{mix}}=120 \mathrm{~s}\right)$. Therefore, $\mathrm{t}_{\mathrm{mix}}=120 \mathrm{~s}$ was enough to mix the slurry. This time was near to the times determined by the image processing method. A mixing process, pausing time of $5 \mathrm{~h}$ and mixing time of $300 \mathrm{~s}$, has been suggested by other researchers $[5,7]$ to produce the most efficiency for anaerobic digesters. These illustrations indicated a strong influence of the biogas recirculation on the flow pattern in agreement with previous studies [8]. Moreover, the biogas injection disrupted the uniform patterns made by the impeller in the digester which is very suitable for a mixing system in the biogas digesters, especially at a low rotation speed. These two reasons, $\mathrm{t}_{\mathrm{mix}}$ reduction and pattern disruption, could improve the biodegradation of organic matters, and thus increase biogas production. However, the CFD 
analysis in Fig. 7 indicates that an excessive injection speed and injection pressure or long injection time may have the opposite effect on pneumatic mixing process. This is in agreement with determined optimum amounts of the biogas injection factors. According to literature [8, $31,32]$, the theoretical findings are adopted for the operation of a real-life anaerobic digester.

\section{Fig. 7}

It is practically impossible to keep all the injection parameters at constant levels for the pneumatic mixers. Even though it is possible to control the mixing system using equipment to a certain extent, this would considerably increase the cost of operations. The range and region optimization based on the overlaying method would then be a handy tool for the operators in such situations. These facts point to the importance of desirability function and overlaying method in this study to clarify the optimum conditions of the pneumatic mixing systems.

\section{Conclusion}

In this study, the best strategy for pneumatic mixing systems using biogas recirculation was determined. For this purpose, mixing characteristics including $\mathrm{Col}_{\mathrm{r}}$ and $\mathrm{t}_{\text {mix }}$ (using image processing base image segmentation technique), and anaerobic digestion quality (based on biogas compounds) were studied using multivariate modeling according to biogas injection parameters. The biogas injection parameters were carefully considered using the CFD. The regression analysis indicated that for a similar mass rate, biogas injection through the mixer produced more $\mathrm{CH}_{4}$ than the other positions. Furthermore, for a low injection repetition, a higher mass flow rate was needed to increase the $\mathrm{CH}_{4}$ content and decrease $\mathrm{t}_{\text {mix }}$. These different interaction effects between the parameters show the importance of having a suitable strategy for biogas injection in the pneumatic mixing systems. All of the models were integrated in the desirability function to determine the best amounts of injection parameters related to the highest 
desirability value. Accordingly, the best amounts of mass flow rate, injection pressure and injection repetition were $0.02 \mathrm{~g} / \mathrm{s}, 2.84$ bar and 3 times (in $24 \mathrm{~h}$ ), respectively. Corresponding suitable ranges determined by region optimization were $0.015-0.028 \mathrm{~g} / \mathrm{s}, 1.5-4.7$ bar and $1-4$ times in $24 \mathrm{~h}$. Further, the best injection position was the injection through the mixer and after that was the injection from floor of digester. The CFD analysis showed that an excessive injection speed and pressure or long injection time may have the opposite effect on pneumatic mixing process. This confirms the importance of region optimization or point optimization. However, determination the optimum ranges is more valuable and more commonplace for practical use in plants than point optimization.

\section{References}

[1] Liao, X., Li, H.: Biogas production from low-organic-content sludge using a high-solids anaerobic digester with improved agitation. Appl. Energy 148, 252-259 (2015) https://doi.org/10.1016/j.apenergy.2015.03.082.

[2] Kariyama, I.D., Zhai, X., Wu, B.: Influence of mixing on anaerobic digestion efficiency in stirred tank digesters: a review. Water Res. 143, 503-517 (2018) https://doi.org/10.1016/j.watres.2018.06.065.

[3] Naegele, H.J., Monch-Tegeder, M., Leonard Haag, N., Oechsner, H.: Effect of substrate pretreatment on particle size distribution in a full-scale research biogas plant. Bioresour. Technol. 172, 396-402 (2014) https://doi.org/10.1016/j.biortech.2014.09.037.

[4] Pietranski, J.F.: Mechanical agitator power requirements for liquid batches. DHonline Course K103 (2 PDH), 1-24 (2012)

[5] Mahmoodi-Eshkaftaki, M., Ebrahimi, R.: The effect of blade angle of turbine impellers on anaerobic digestion efficiency in stirred digesters. Energy 178, 772-780 (2019) https://doi.org/10.1016/j.energy.2019.04.183. 
[6] Zhang, Q., Yong, Y., Mao, Z.S., Yang, C., Zhao, C.: Experimental determination and numerical simulation of mixing time in a gas-liquid stirred tank. Chem. Eng. Sci. 64, 29262933 (2009) https://doi.org/10.1016/j.ces.2009.03.030.

[7] Mahmoodi-Eshkaftaki, M., Houshyar, E.: Biogas recirculation technology: effect on biogas purification, slurry characteristics, microbial activity and energy consumption. Environ. Technol. Innov. 19, 100867 (2020) https://doi.org/10.1016/j.eti.2020.100867.

[8] Meister, M., Rezavand, M., Ebner, C., Pumpel, T., Rauch, W.: Mixing non-Newtonian flows in anaerobic digesters by impellers and pumped recirculation. Adv. Eng. Softw. 115, 194-203 (2018) http://dx.doi.org/10.1016/j.advengsoft.2017.09.015.

[9] $\mathrm{Wu}, \mathrm{B} .: \mathrm{CFD}$ simulation of gas and non-Newtonian fluid two-phase flow in anaerobic digester. Water Res. 44, 3861-3874 (2010) https://doi.org/10.1016/j.watres.2010.04.043.

[10] Wu, B.: CFD simulation of gas mixing in anaerobic digesters. Comput. Electron. Agric. 109, 278-286 (2014) https://doi.org/10.1016/j.compag.2014.10.007.

[11] Leonizo, G.: Study of mixing systems and geometric configurations for anaerobic digesters using CFD analysis. Renew. Energy 123, 578-589 (2018) https://doi.org/10.1016/j.renene.2018.02.071.

[12] Meroney, R.N., Colorado, P.E.: CFD simulation of mechanical draft tube mixing in anaerobic digester tanks. Water Res. 43, 1040-1050 (2009) https://doi.org/10.1016/j.watres.2008.11.035.

[13] Cozma, P., Wukovits, W., Mamaliga, I., Friedl, A., Gavrilescu, M.: Modeling and simulation of high-pressure water scrubbing technology applied for biogas upgrading. Clean Technol. Environ. Policy 17, 373-391 (2015) Doi: 10.1007/s10098-014-0787-7.

[14] Sun, Q., Li, H., Yan, J., Liu, L., Yu, Z., Yu, X.: Selection of appropriate biogas upgrading technology-A review of biogas cleaning, upgrading and utilization. Renew. Sustain. Energy Rev. 51, 521-532 (2015) Doi:10.1016/j.rser.2015.06.029. 
[15] Mahmoodi-Eshkaftaki, M., Ebrahimi, R.: Assess a new strategy and develop a new mixer to improve anaerobic microbial activities and clean biogas production. J. Clean. Prod. 206, 797-807 (2019) https://doi.org/10.1016/j.jclepro.2018.09.024.

[16] Siddique, N.I., Abdul Munaim, M.S., Abdul Wahid, Z.: Role of biogas recirculation in enhancing petrochemical wastewater treatment efficiency of continuous stirred tank reactor. J. Clean. Prod. 91, 229-234 (2015) http://dx.doi.org/10.1016/j.jclepro.2014.12.036.

[17] Yuan, T., Cheng, Y., Wang, X., Yu, Y., Zhang, Z., Lei, Z., Shimizu, K., Utsumi, M., Adachi, Y., Lee, D.J.: A novel anaerobic digestion system coupling biogas recirculation with $\mathrm{MgCl}_{2}$ addition for multipurpose sewage sludge treatment. J. Clean. Prod. 230, 499-507 (2019) https://doi.org/10.1016/j.jclepro.2019.05.124.

[18] Morero, B., Groppelli, E.S., Campanella, E.A.: Evaluation of biogas upgrading technologies using a response surface methodology for process simulation. J. Clean. Prod. 141, 978-988 (2017) http://dx.doi.org/10.1016/j.jclepro.2016.09.167.

[19] Goos, P., Donev, A.N.: Blocking response surface designs. Comput. Stat. Data Anal. 51, 1075-1088 (2006) https://doi.org/10.1016/j.csda.2005.11.003.

[20] Kaparaju, P.L.N., Rintala, J.A.: Effects of solid-liquid separation on recovering residual methane and nitrogen from digested dairy cow manure. Bioresour. Technol. 99, 120-127 (2008) https://doi.org/10.1016/j.biortech.2006.11.046.

[21] Tissot, S., Farhat, M., Hacker, D.L., Anderlei, T., Kuhner, M., Comninellis, C., Wurm, F.: Determination of a scale-up factor from mixing time studies in orbitally shaken bioreactors. Biochem. Eng. J. 52, 181-186 (2010) https://doi.org/10.1016/j.bej.2010.08.005.

[22] Wang, H., Li, J., Cheng, M., Zhang, F., Wang, X., Fan, J., Wu, L., Fang, D., Zou, H., Xiang, Y.: Optimal drip fertigation management improves yield, quality, water and nitrogen use efficiency of greenhouse cucumber. Sci. Hortic. 243, 357-366 (2019) https://doi.org/10.1016/j.scienta.2018.08.050. 
[23] ANSYS- Fluent Inc, Fluent 18.0. ANSYS-Fluent Inc, Lebanon, NH (2009)

[24] Wu, B., Chen, S.: CFD simulation of non-Newtonian fluid flow in anaerobic digesters. Biotechnol. Bioeng. 99, 700-711 (2008)

[25] Arun, V.V., Saharan, N., Ramasubramanian, V., Babitha Rani, A.M., Salin, K.R., Sontakke, R., Haridas, H., Pazhayamadom, D.G.: Multi-response optimization of Artemia hatching process using split-split-plot design-based response surface methodology. Sci. Rep. 7, 1-13 (2017) https://doi.org/10.1038/srep40394,40394.

[26] Bakraoui, M., Karouach, F., Ouhammou, B., Aggour, M., Essamri, A., El Bari, H.: Biogas production from recycled paper mill wastewater by UASB digester: optimal and mesophilic conditions. Biotechnol. Rep. 25, e00402 (2020) https://doi.org/10.1016/j.btre.2019.e00402.

[27] Menon, A., Wang, J.Y., Giannis, A.: Optimization of micronutrient supplement for enhancing biogas production from food waste in two-phase thermophilic anaerobic digestion. Waste Manage. 59, 465-475 (2016) https://doi.org/10.1016/j.wasman.2016.10.017.

[28] Tetteh, E., Ansah Amano, K.O., Asante-Sackey, D., Armah, E.: Response surface optimization of biogas potential in co-digestion of miscanthus fuscus and cow dung. Int. J. Technol. 5, 944-954 (2018) https://doi.org/10.14716/ijtech.v9i5.1467.

[29] Roy, D., Samanta, S., Ghosh, S.: Performance optimization through response surface methodology of an integrated biomass gasification based combined heat and power plant employing solid oxide fuel cell and externally fired gas turbine. Energy Convers. Manag. 222, 113182 (2020) https://doi.org/10.1016/j.enconman.2020.113182.

[30] Sun, C., Liu, R., Cao, W., Li, K., Wu, L.: Optimization of sodium hydroxide pretreatment conditions to improve biogas production from asparagus stover. Waste Biomass Valor. 10, 121-129 (2019) https://doi.org/10.1007/s12649-017-0020-0. 
[31] Hurtado, F.J., Kaiser, A.S., Zamora, B.: Fluid dynamic analysis of a continuous stirred tank reactor for technical optimization of wastewater digestion. Water Res. 71, 282-293 (2015) http://dx.doi.org/10.1016/j.watres.2014.11.053.

[32] Kruczek, G., Przybyła, G., Ziolkowski, L., Adamczyk, W.P.: Comparative assessment of the application of methane and biogas in energy production: an experimental and numerical investigation. $\quad$ Renew. Energy 143, 1519-1530 (2019) doi: https://doi.org/10.1016/j.renene.2019.05.087.

Table 1 Statistical information of the experiments including independent variables and responses

\begin{tabular}{clcccc}
\hline Factor & Independent variables & Type & Range & Mean & Std. Dev. \\
\hline$x_{1}$ & Injection mass rate $(\mathrm{g} / \mathrm{s})$ & Numeric & $0.009-0.025$ & 0.017 & 0.006 \\
$x_{2}$ & Injection pressure $(\mathrm{bar})$ & Numeric & $1-5$ & 2.595 & 1.530 \\
$x_{3}$ & Injection repetition & Numeric & $2-4$ & 2.762 & 0.700 \\
$x_{4}$ & Injection position & Numeric & $0-2$ & 0.905 & 0.944 \\
Response & Dependent variables & Model trans. & Range & Mean & Std. Dev. \\
& & & & & \\
$y_{1}$ & $\mathrm{CH}_{4}(\%)$ & Power & $5-74$ & 39.524 & 18.745 \\
$y_{2}$ & $\mathrm{H}_{2} \mathrm{~S}(\%)$ & Power & $0.1-4.0$ & 1.562 & 1.048 \\
$y_{3}$ & $\mathrm{CO}(\%)$ & None & $0.005-0.050$ & 0.022 & 0.010 \\
$y_{4}$ & $\mathrm{O}_{2}(\%)$ & None & $7.10-19.10$ & 11.786 & 2.588 \\
$y_{5}$ & $\mathrm{CO}_{2}(\%)$ & Power & $6.79-57.23$ & 34.974 & 15.215 \\
$y_{6}$ & $\mathrm{Color}_{\text {rating }}(\%)$ & Power & $1.9-5.2$ & 3.362 & 1.077 \\
$y_{7}$ & Mixing time $(\mathrm{s})$ & Power & $123.5-150.1$ & 136.143 & 8.225 \\
\hline
\end{tabular}


Table 2 Mathematical models to estimate the biogas compounds and mixing characteristics

\begin{tabular}{|c|c|c|c|c|c|c|c|c|c|c|c|c|}
\hline \multirow{2}{*}{ Parameters } & \multirow{2}{*}{$\begin{array}{l}\text { Eq. } \\
\text { No }\end{array}$} & \multirow{2}{*}{ Mathematical models } & \multirow{2}{*}{$r_{i}$} & \multirow{2}{*}{ df } & \multicolumn{2}{|c|}{ F-value } & \multicolumn{2}{|c|}{$\mathrm{p}$-value $($ Prob $>\mathrm{F})$} & \multicolumn{4}{|c|}{ Summary statistics } \\
\hline & & & & & Model & $\mathrm{LF}$ & Model & $\mathrm{LF}$ & $\mathrm{R}^{2}$ & $\mathrm{AR}^{2}$ & $\mathrm{PR}^{2}$ & $\mathrm{AP}$ \\
\hline $\mathrm{CH}_{4}(\%)$ & 13 & $\begin{array}{l}\left(\mathrm{CH}_{4}+5\right)^{0.77}=22.52-3.09 x_{1}+0.33 x_{2}+0.77 x_{3}+4.28 x_{4}- \\
5.81 x_{1} x_{2}-0.04 x_{1} x_{3}-6.45 x_{2}{ }^{2}\end{array}$ & 5 & 7 & 5.94 & 0.29 & $0.0029^{* *}$ & $0.940^{\mathrm{ns}}$ & 0.76 & 0.63 & 0.39 & 9.34 \\
\hline $\mathrm{H}_{2} \mathrm{~S}(\%)$ & 14 & $\begin{array}{l}\left(\mathrm{H}_{2} \mathrm{~S}+5\right)^{0.67}=3.44+0.18 x_{1}+0.061 x_{2}-0.041 x_{3}- \\
0.241 x_{4}+0.275 x_{1} x_{3}-0.219 x_{1} x_{4}-0.346 x_{2} x_{4}\end{array}$ & 4 & 7 & 7.08 & 0.36 & $0.0013^{* *}$ & $0.906^{\mathrm{ns}}$ & 0.79 & 0.68 & 0.35 & 10.29 \\
\hline $\mathrm{CO}_{2}(\%)$ & 15 & $\begin{array}{l}\left(\mathrm{CO}_{2}+3\right)^{0.7}=10.3-0.995 x_{1}-0.605 x_{2}-2.67 x_{4}+ \\
2.91 x_{1} x_{2}+2.18 x_{1} x_{3}-0.665 x_{1} x_{4}+3.177 x_{2}{ }^{2}\end{array}$ & 4 & 7 & 5.74 & 0.40 & $0.0034^{* *}$ & $0.884^{\mathrm{ns}}$ & 0.76 & 0.62 & 0.34 & 8.83 \\
\hline $\mathrm{CO}(\%)$ & 16 & $\begin{array}{l}\mathrm{CO}=0.022+2.7 \times 10^{-3} x_{1}+3.17 \times 10^{-3} x_{2}-5.8 \times 10^{-3} x_{4}+ \\
5 \times 10^{-3} x_{1} x_{2}-5 \times 10^{-3} x_{2} x_{4}\end{array}$ & 3 & 5 & 4.30 & 0.60 & $0.0126^{*}$ & $0.773^{\text {ns }}$ & 0.59 & 0.45 & 0.19 & 9.19 \\
\hline $\mathrm{O}_{2}(\%)$ & 17 & $\begin{array}{l}\mathrm{O}_{2}=1.7+0.0057 x_{1}+0.0055 x_{2}-0.04 x_{4}-0.035 x_{1} x_{4}- \\
0.041 x_{2} x_{4}\end{array}$ & - & 5 & 7.57 & 0.60 & $0.0010^{* *}$ & $0.771^{\mathrm{ns}}$ & 0.72 & 0.62 & 0.38 & 10.45 \\
\hline $\operatorname{Col}_{\mathrm{r}}(\%)$ & 18 & $\begin{array}{l}\left(\mathrm{Col}_{\mathrm{r}}+1\right)^{0.56}=2.185+0.274 x_{1}+0.302 x_{2}+0.089 x_{4}+ \\
0.104 x_{1} x_{4}+0.118 x_{1}^{2}+0.093 x_{4}^{2}\end{array}$ & 4 & 6 & 49.72 & 7.50 & $<0.0001^{* *}$ & $0.061^{\mathrm{ns}}$ & 0.96 & 0.94 & 0.91 & 21.63 \\
\hline $\mathrm{T}_{\text {mix }}(\mathrm{s})$ & 19 & $\begin{array}{l}\left(\mathrm{t}_{\operatorname{mix}}+3\right)^{-2.44}=5.85 \times 10^{-6}+8.06 \times 10^{-7} x_{1}+8.03 \times \\
10^{-7} x_{2}+2.90 \times 10^{-7} x_{4}+1.91 \times 10^{-7} x_{1} x_{4}+3.48 \times 10^{-7} x_{4}{ }^{2}\end{array}$ & 3 & 5 & 34.97 & 1.21 & $<0.0001^{* *}$ & $0.49^{\text {ns }}$ & 0.92 & 0.89 & 0.85 & 17.41 \\
\hline
\end{tabular}


Table 3 Optimal quantities of the biogas compounds and mixing characteristics for optimum amounts of input factors

\begin{tabular}{|c|c|c|c|c|c|c|c|c|c|}
\hline Response & Run 1 & $\left(\begin{array}{l}x_{1}=0.02 \\
x_{3}=2.64\end{array}\right.$ & $\left.\begin{array}{l}x_{2}=2.84 \\
x_{4}=1.95\end{array}\right)$ & Run 2 & $\left(\begin{array}{l}x_{1}=0.02 \\
x_{3}=2.45\end{array}\right.$ & $\left.\begin{array}{l}x_{2}=2.82 \\
x_{4}=1.91\end{array}\right)$ & Run 3 & $\left(\begin{array}{c}x_{1}=0.015 \\
x_{3}=2.95\end{array}\right.$ & $\left.\begin{array}{ll}5 & x_{2}=3.56 \\
5 & x_{4}=0.92\end{array}\right)$ \\
\hline & Mean & Std. Dev. & $95 \%$ PI & Mean & Std. Dev. & $95 \%$ PI & Mean & Std. Dev. & $95 \%$ PI \\
\hline $\mathrm{CH}_{4}(\%)$ & 63.323 & 12.779 & [49.83-77.48] & 63.307 & 12.779 & [49.83-77.44] & 44.797 & 11.879 & {$[34.44-55.70]$} \\
\hline $\mathrm{H}_{2} \mathrm{~S}(\%)$ & 0.685 & 0.559 & [0.21-1.17] & 0.687 & 0.559 & [0.22-1.17] & 1.825 & 0.594 & [1.37-2.29] \\
\hline $\mathrm{CO}_{2}(\%)$ & 15.477 & 7.842 & [7.76-24.47] & 15.510 & 7.845 & [7.78-24.51] & 30.911 & 9.431 & [23.03-39.41] \\
\hline $\mathrm{CO}(\%)$ & 0.018 & 0.007 & [0.01-0.02] & 0.018 & 0.007 & [0.01-0.02] & 0.027 & 0.007 & {$[0.02-0.03]$} \\
\hline $\mathrm{O}_{2}(\%)$ & 9.602 & 1.358 & {$[8.52-10.76]$} & 9.605 & 1.357 & [8.52-10.76] & 12.585 & 1.608 & [11.52-13.71] \\
\hline $\mathrm{Col}_{\mathrm{r}}(\%)$ & 4.041 & 0.286 & [3.77-4.31] & 4.035 & 0.286 & [3.77-4.31] & 3.138 & 0.262 & [2.86-3.42] \\
\hline $\mathrm{t}_{\text {mix }}(\mathrm{s})$ & 128.974 & 0.096 & [127.13-130.91] & 128.977 & 0.096 & [127.16-130.93] & 136.110 & 0.131 & [133.72-138.65] \\
\hline
\end{tabular}

\section{Figure captions}

Fig. 1 Schematic illustration of the anaerobic digester with both mechanical and pneumatic mixing systems

Fig. 2 Image processing process to determine the color changes, color rating and mixing time

Fig. 3 Predicted values versus actual values of the biogas compounds and the mixing characteristics using the developed models; (a) $\mathrm{CH}_{4}$; (b) $\mathrm{H}_{2} \mathrm{~S}$; (c) $\mathrm{CO}_{2}$; (d) $\mathrm{CO}$; (e) $\mathrm{O}_{2}$; (f) Color rating; (g) Mixing time

Fig. 4 Response graphs of more important biogas compounds and mixing characteristics as a function of significant interactions detected by the developed models

Fig. 5 Desirability changes VS. independent factors of biogas injection

Fig. 6 Optimum region of the injection factors by overlaying the responses; (a) Primary optimum region; (b) Optimum region in $90 \%$ of the best amount of each response (an optimum region was not found); (c) Optimum region in $70 \%$ of the best amount of each response

Fig. 7 Volume fraction contours of the slurry for the biogas injection from floor of digester with optimum mass rate and injection pressure of $0.015 \mathrm{~g} / \mathrm{s}$ and $3.56 \mathrm{bar}$, respectively 


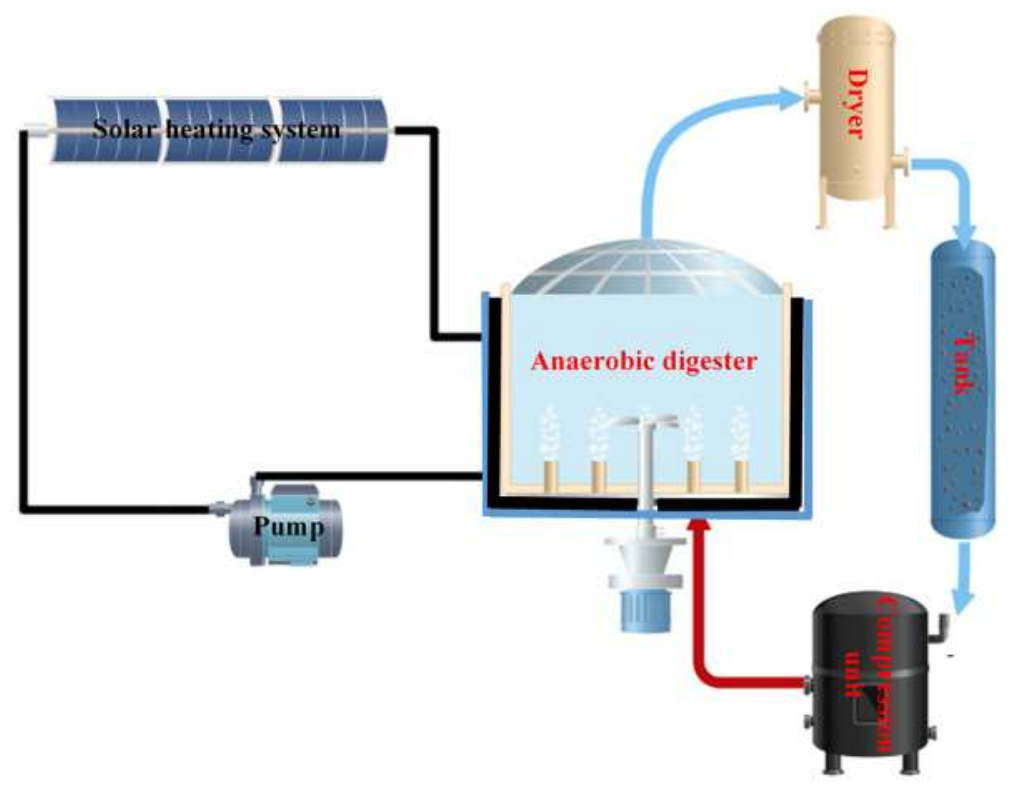

Fig. 1 


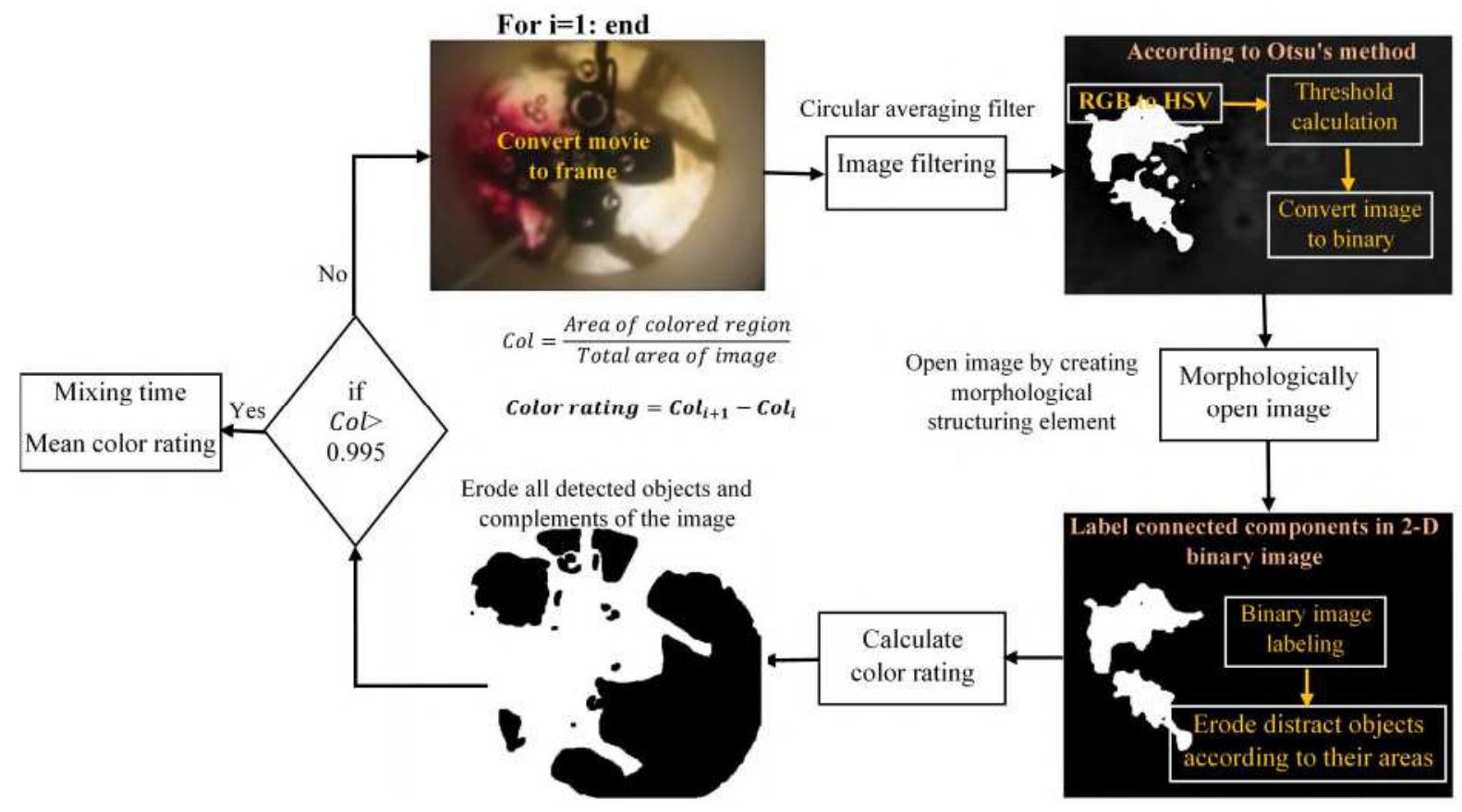

Fig. 2 

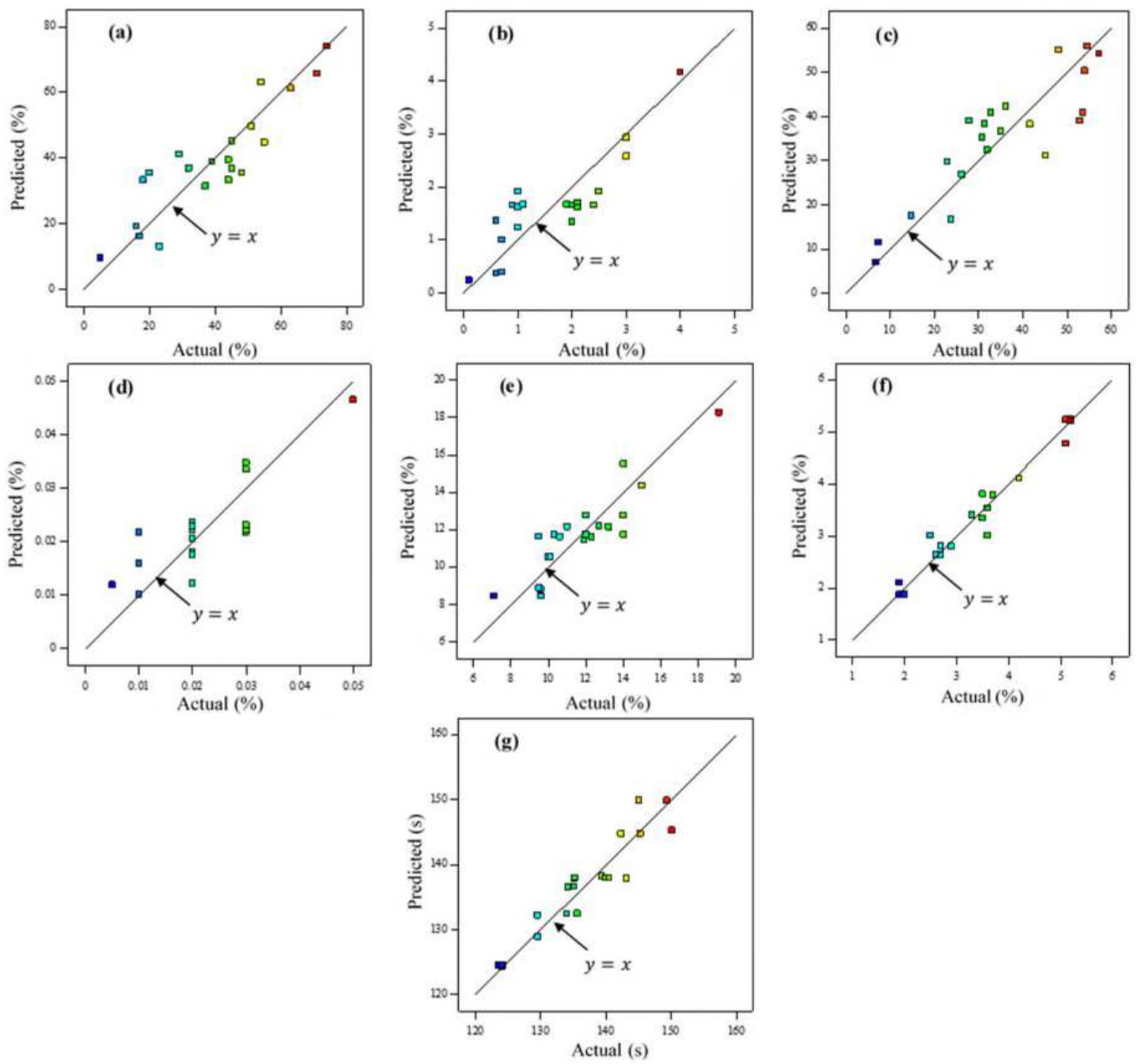

Fig. 3 

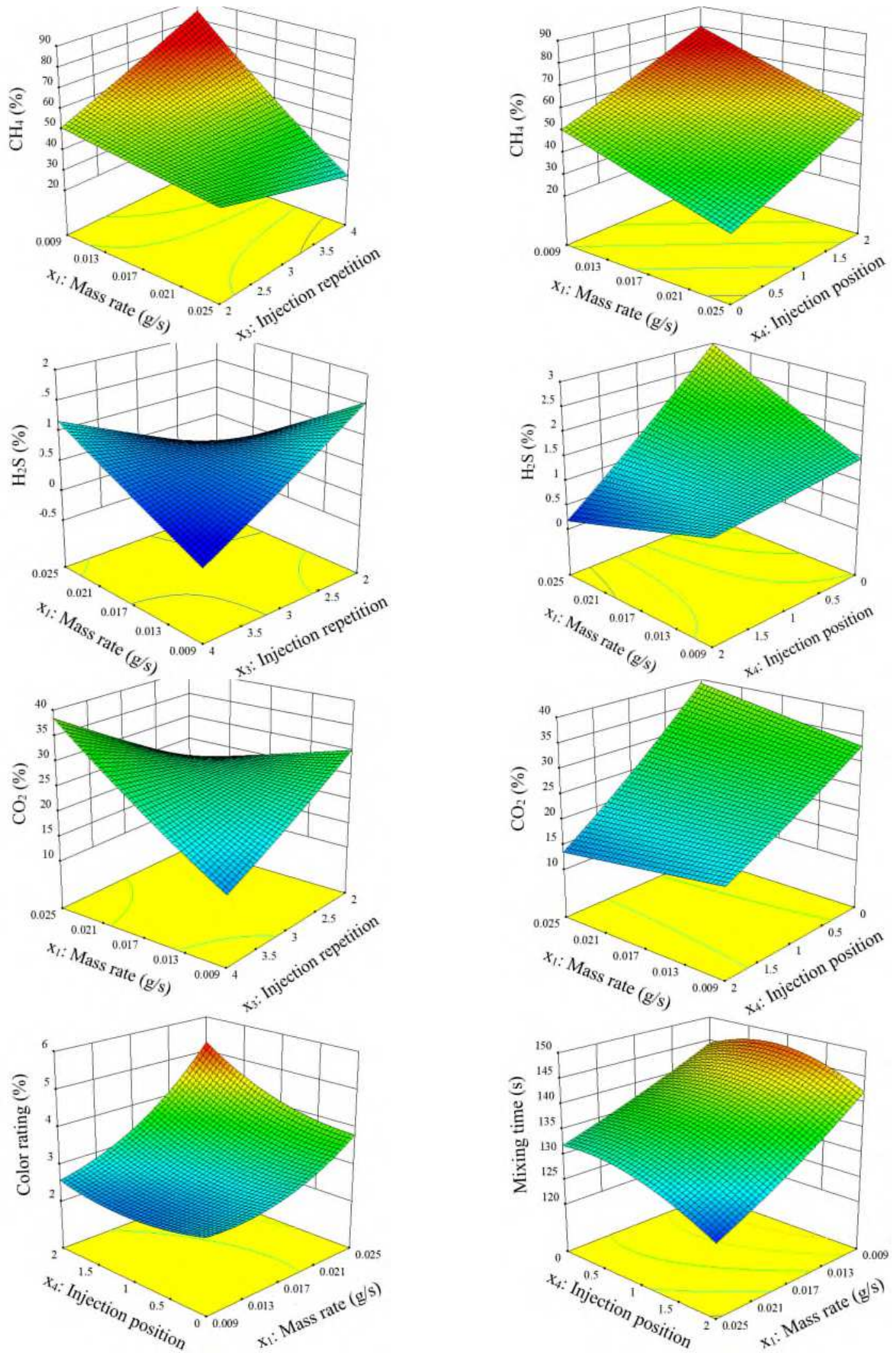

Fig. 4 

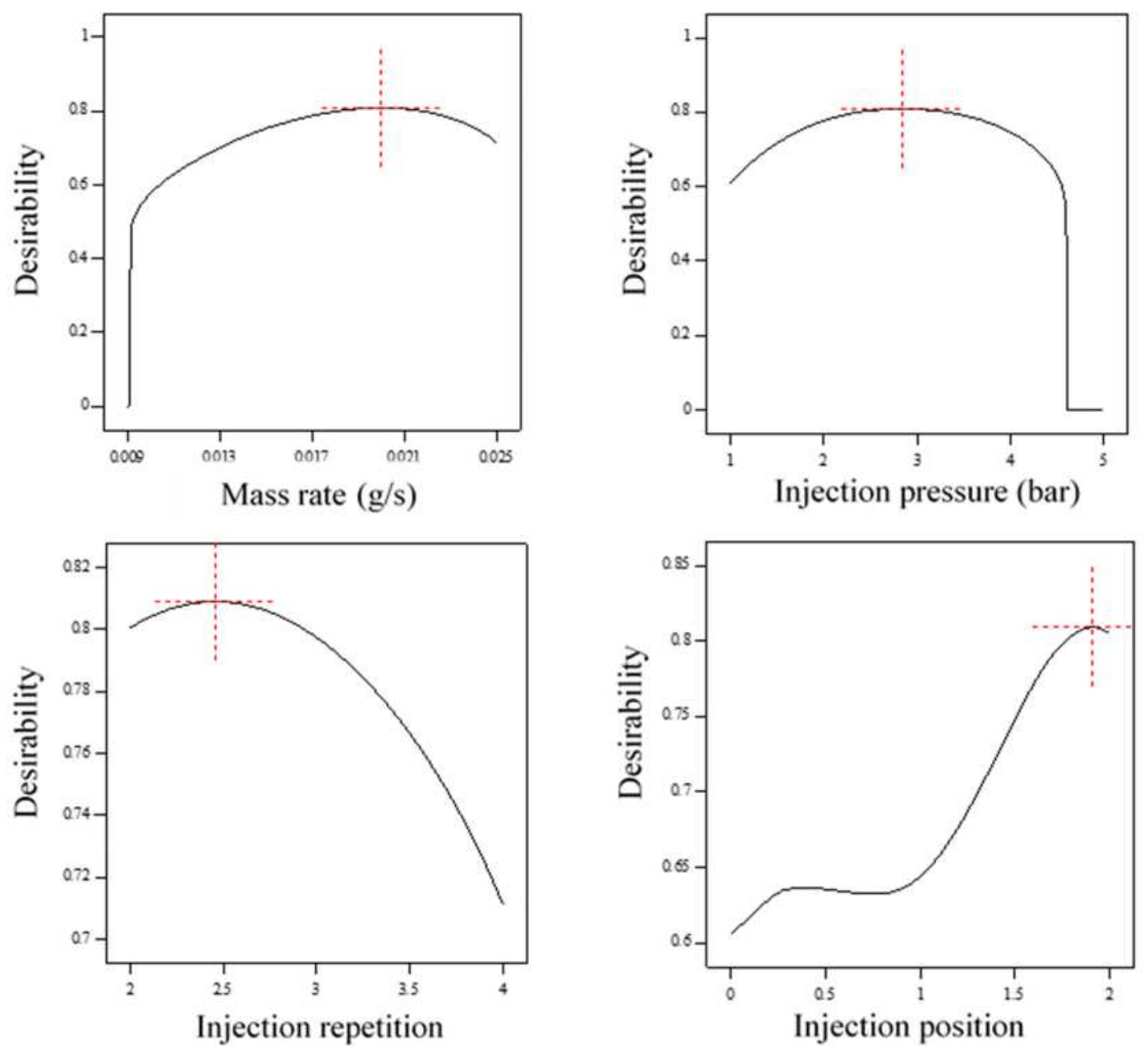

Fig. 5 

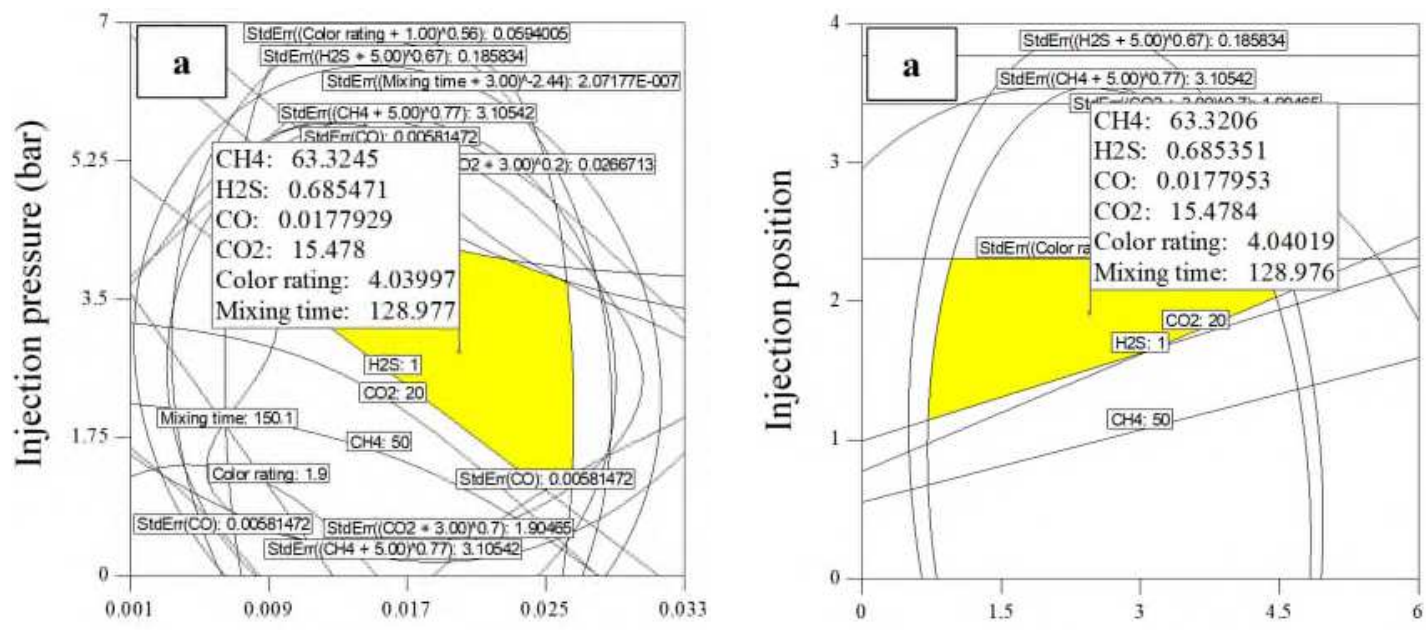

Mass rate $(\mathrm{g} / \mathrm{s})$
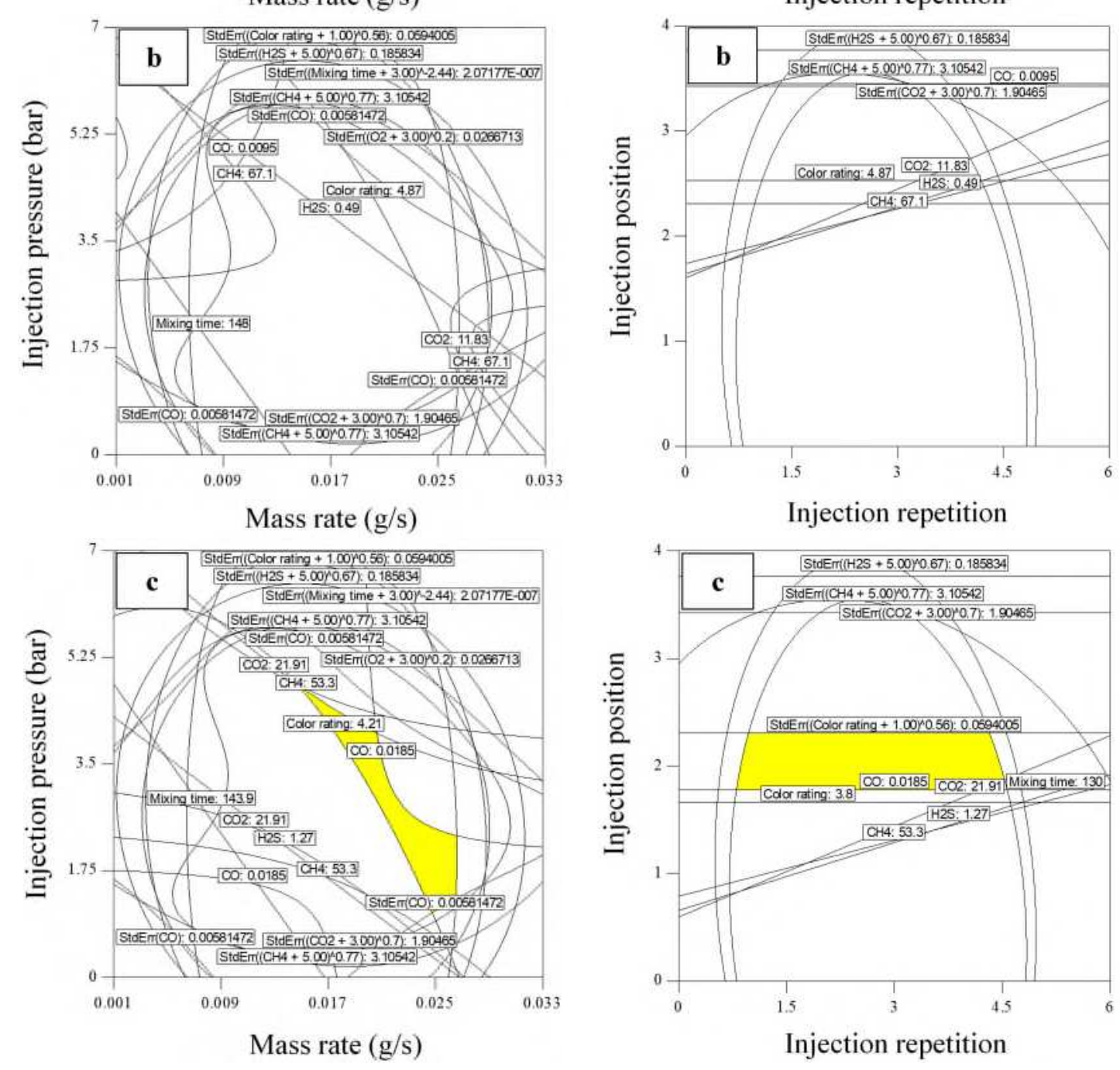

Fig. 6 

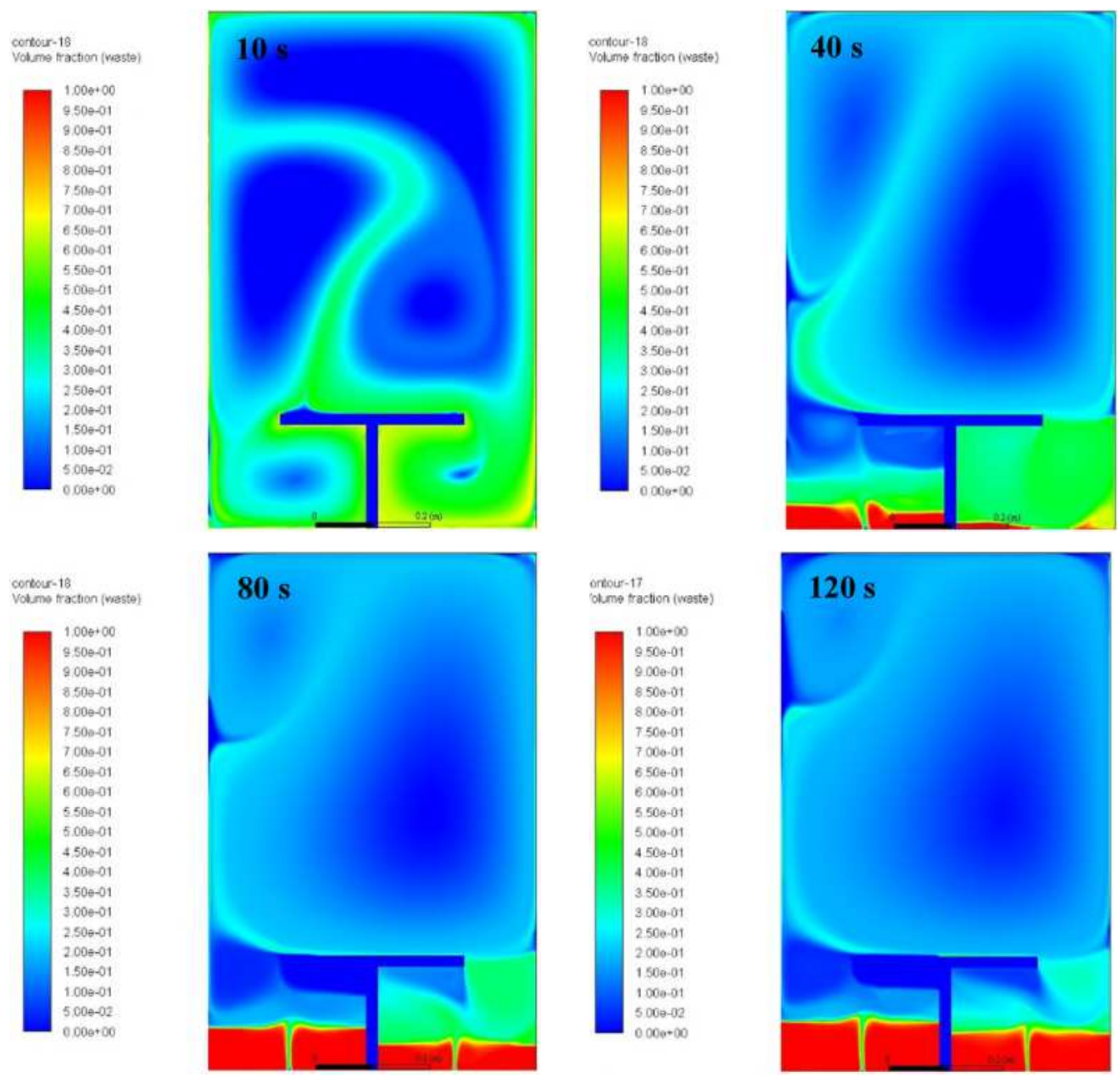

Fig. 7 